\title{
ÜÇÜNCÜ KRANIAL SINIR PARALIZISI iLE GELEN LEPTOMENINGEAL METASTAZ OLGUSU
}

\author{
A CASE OF LEPTOMENINGEAL METASTASIS WITH THIRD CRANIAL \\ NERVE PARALYSIS
}

Fatma ŞiMŞEK' ${ }^{1}$, Filiz AKTAŞ ${ }^{1}$, Alper EREN ${ }^{1}$, Gökhan AYDOĞAN ${ }^{1}$
${ }^{1}$ Atatürk Üniversitesi Tıp Fakültesi Nöroloji Anabilim Dalı

Cite this article as: Şimşek F, Aktaş F, Eren A, Aydoğan G. A Case of Leptomeningeal Metastasis with Third Cranial Nerve Paralysis. Med J SDU 2020; 27(2): 242-244.

Öz

Leptomeningeal karsinomatozis nadir görülen nörolojik bir komplikasyondur. Sistemik tümörlerin birçoğunda beyin metastazı görülmesine rağmen leptomeningeal metastaz görülmesi nadirdir. Meme kanserli hastalarda leptomeningeal tutulum oranı düşük olmakla birlikte en sık leptomeningeal metastaza neden olan tümör meme kanseridir. Tanı anında hastaların sistemik hastalıkları çoğunlukla ileri evrededir. Tanı için BOS histopatolojik incelemesi ve dikkatli bir şekilde kontrastlı beyin görüntülemelerinin değerlendirilmesi önemlidir. Bu hastalarda beyin görüntülemeleri tamamen normal olabileceğinden BOS incelemesi ayrı bir öneme sahiptir. Leptomeningeal metastaz gelişen hastalarda yaşam süresi kısa olup, hastalara çoğunlukla palyatif tedavi önerilir. Palyatif tedaviye erken başlanması hastaların yaşam standartlarının daha uzun süre daha iyi seyretmesini sağlayabildiği için leptomeningeal metastazda da erken tanı önemlidir. Bu yazıda, meme kanseri olan ve üçüncü kranial sinir paralizisi ile nöroloji kliniğinde takip edilen leptomeningeal metastazlı bir olguyu nadir görülen klinik bir tablo olması nedeni ile sunduk.

Anahtar Kelimeler: Meme kanseri; leptomeningeal karsinomatozis; üçüncü kranial sinir paralizisi

\section{Abstract}

Leptomeningeal carsinomatozis is a rare neurologic complication. In many of the systemic tumors, in spite of being seen the brain metastasis, being seen leptomeningeal metastasis is rare. In the patients with breast cancer rate of leptomeningeal involvement is low, but the tumor which causes the most common leptomeningeal metastasis is breast cancer. At diagnosis time, the systemic diseases of the patients is usually in the advanced level. Being examined as the histopathological of CSF and evaluated of the contrasty brain imaging carefully are important for diagnosis. Since brain imaging can be completely normal in these patients, CSF examination has a special importance.. The life process is short in the patients developed leptomeningeal metastasis, it is usually suggested the palliative treatment. Early diagnosis is also important in leptomeningeal metastasis as early initiation of palliative treatment may help patients to maintain better life standards for longer. In this report, we presented a case with leptomeningeal metastasis which is breast cancer and is followed with third cranial nerve paralizise at the neurology clinic because of being a clinic table which is seen rarely.

Keywords: Breast cancer; leptomeningeal carcinomatosis; the third cranial nerve palsy

İletişim kurulacak yazar/Corresponding author: klamaks@hotmail.com

Müracaat tarihi/Application Date: 18.04.2019 - Kabul tarihi/Accepted Date: 24.05.2019

Available online at http://dergipark.gov.tr/sdutfd

Makaleye http://dergipark.gov.tr/sdutfd web sayfasından ulaşılabilir. 


\section{Giriş}

Leptomeningeal karsinomatozis (LK), leptomeninks ve subaraknoid alanların malign hücreler tarafından infiltre edilmesi ile ortaya çıkan, birçok sistemik tümörde görülebilen nörolojik bir komplikasyondur. Meme kanserinin nadir görülen bir komplikasyonudur ve meme kanserinde görülme oranı \%5'dir $(1,2)$. En sık görülen belirtiler kranial sinir felçleri, baş ağrısı, poliradikülopati, inkontinans, konfüzyonel durum, duyu bozukluğu şeklindedir $(3,4)$. LK, kanserli hastaların nörolojik fonksiyonlarında ve becerilerinde ciddi bozulmalara yol açabilmektedir. Leptomeningeal tutulum saptanması kötü prognoza işaret eder ve LK saptanan hastalarda ortalama yaşam süresi 4-6 ay kadardır. Bu hastalara palyatif tedavi uygulanmaktadır. Burada meme kanseri tanısı olup üçüncü kranial sinir paralizisi nedeni ile tetkik edilen ve LK saptanan bir olgu nadir bir tablo olması nedeni ile sunulmuştur. Hastadan yazılı onam alınmıştır.

\section{Olgu}

Altı ay önce meme kanseri tanısı alan 33 yaşındaki kadın hasta başının sağ tarafında 8-10 saat kadar devam eden şiddetli baş ağrısı ve sonrasında sağ göz kapağında düşme olması nedeni ile nöroloji polikliniğinde değerlendirildi. Hastanın baş ağrısı zonklayıcı karakterde, eforla artış göstermemiş ve bulantı-kusma eşlik etmişti. Daha öncesinde olan benzer baş ağrısı şikayeti tarif etmiyordu. Görmede azalma ve gözde kızarıkıı yoktu. Özgeçmiş; altı ay önce meme kanseri tanısı alan hastaya iki kür kemoterapi (transtuzumab-paklitaksel) verilmişti. Sogeçmiş; özellik yoktu. Nörolojik muayene; sağ gözde pitoz, sağ göz yukarı-aşağı ve içe bakışı kısıtlı, sağ pupil midriyatik, sağ gözde direk ve indirek ışık refleksi alınmıyordu. Diğer nörolojik muayenesi normaldi. Tam kan sayımı ve biyokimya parametreleri, sedimentasyon, C-reaktif protein normaldi. Dış merkezli çekilen kranial manyetik rezonans görüntüleme (MRG), difüzyon MRG, $M R$ anjiyografi ve MR venografi normal görünümde idi. Hastanın dış merkezli normal olarak değerlendirilen kontrastlı kranial MRG' leri yeniden incelendiğinde meninks lokalizasyonunda nodüler kalınlaşmalar (resim 1), sağ kavernöz sinüste $2,5 \times 1 \mathrm{~cm}$ ebatlı belirgin kontrastlanan leptomeningeal metastatik kitle lezyon görüldü (resim 2, 3). Hastanın üçüncü kranial sinir paralizisinin etiyolojisinde meme kanserine bağlı LK tesbit edildi. Çekilen pozitron emisyon tomografide (PET-CT) kemik metastazı saptanan hastaya radyasyon onkoloji tarafından palyatif radyoterapi önerildi.

\section{Tartışma}

Leptomeningeal karsinomatozis (LK) sistemik tümörlerin nadir görülen bir komplikasyonudur. Kanser hücrelerinin leptomeninkslere yayılımı hematojen veya lenfatik yayılım ile perivasküler, perinöral, endonöral yapılara olabilir. Meme kanserinden kaynaklanan LK,

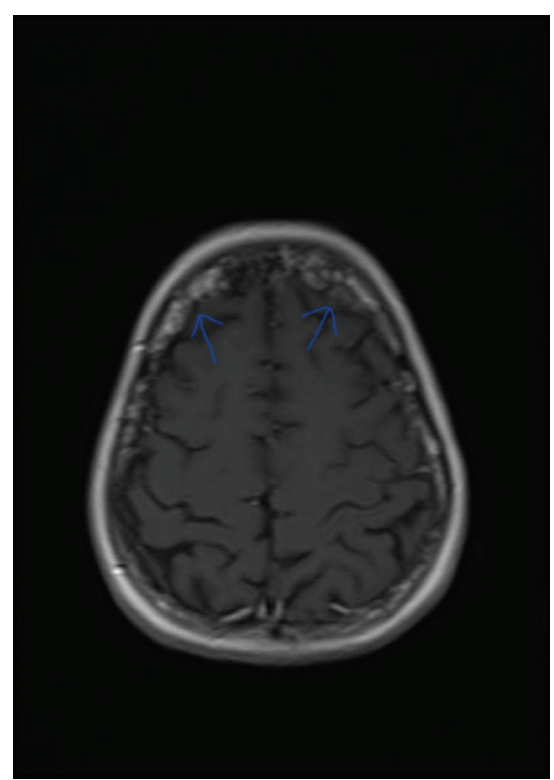

Resim 1: Postkontrast T1 MRG'de yer yer meninks düzeyinde nodüler kalınlaşmalar görülmektedir (oklar).
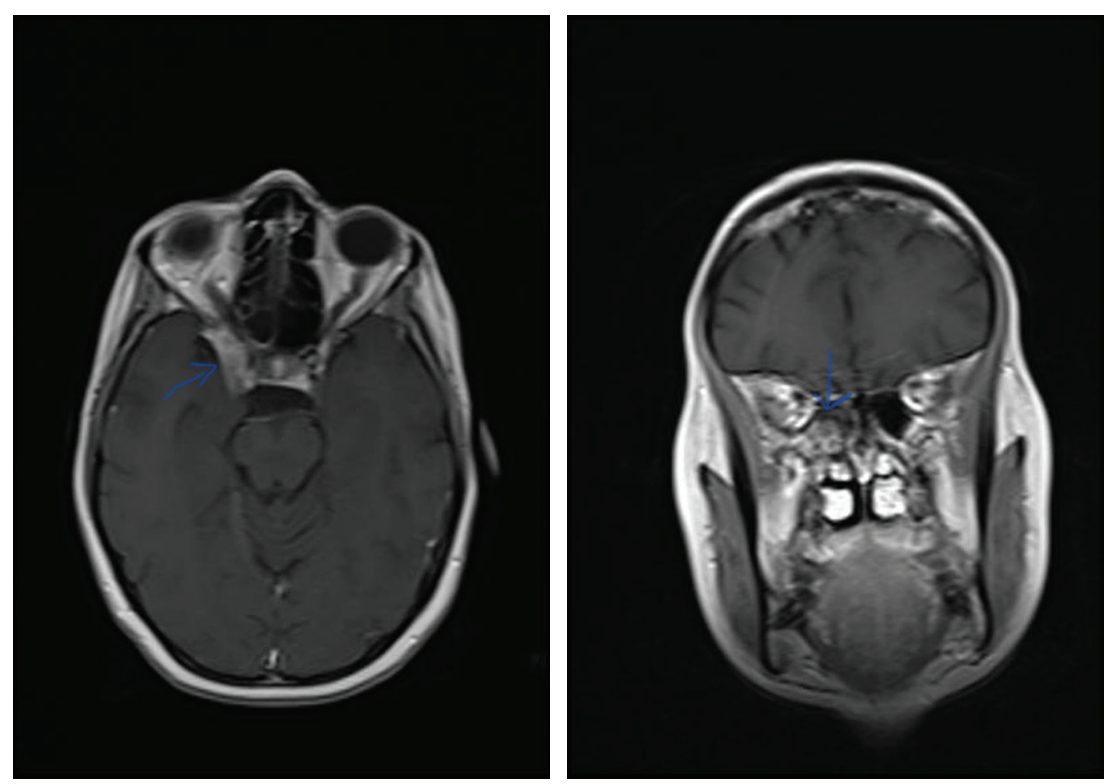

Resim 2-3: Postkontrast aksiyel ve koronal kesitlerde T1 MRG'de sağ kavernöz sinüste belirgin kontrastlanan leptomeningeal metastatik kitle lezyon (oklar). 
diğer malignitelere sekonder LK ile karşılaştırıldığında en iyi prognoza sahip olmasına rağmen agresif olan bazı hastalarda 4 aya kadar uzayan sağ kalım süresi ile hala kötü prognozludur $(5,6)$.

LK de sık görülen belirti ve bulgular; baş ağrısı, radiküler ağrı, kranial sinir felçleri, görme bozuklukları, işitme kaybı, nöbetler ve kauda ekuina sendromudur. Bazen ani şuur bozukluğu ile karşımıza çıkabilir. Bulantı, kusma, pozisyonel baş ağrısı ve uyku hali obstrüktif hidrosefali ile ilişkili semptomlardır ve BOS akışının zarar görmesinden dolayı LK'lı hastaların yarısından fazlasında ortaya çıkabilir. Hastaların \%80'i tanı anında semptomatiktir ve asıl şikayet baş ağrısıdır (7). Hastamızda ilk semptomlar baş ağrısı, bulantı, kusma olup bunu göz kapağında düşüklük ve göz hareketlerinde kısıtlılık şeklinde üçüncü kranial sinir paralizisi takip etmişti. Göz dibi muayenesi normal olup baş ağrısı şiddeti pozisyonla değişmiyordu. Baş ağrısının şiddeti azalınca bulantı-kusma şikayeti rahatlamıştı. Görüntülemelerinde hidrosefali ile uyumlu görüntü yoktu.

LK'de, MRG' nin meningeal tutulumu göstermesi açısından BT'ye üstünlüğü olmakla birlikte her iki görüntülemede tamamen normal olabilir. Meningeal karsinomatozisin asıl tanısı BOS' un sitolojik incelemesi ve biyopsi materyalinin histopatolojik incelenmesidir. Hastamızda çekilen kranial kontrastsız MRG normal iken kontrastlı çekimde meningeal nodüler kontrastlanma görülmekteydi. Kontrastlı MRG' sinin dış merkezde normal değerlendirilmesi dikkat edilmezse bu durumun gözden kaçabileceğini göstermektedir. MRG'de nodüler tutulum izlenen ve meme kanseri tanısı olan hastada BOS sitolojik incelemesi yapılmadı. Görüntülemesi normal olan hastalarda kesin tanı için BOS incelemesi yapılması gereklidir.

Sonuç olarak; maligniteli hastalarda tek bir nörolojik semptom görülmesi durumunda bile meningeal karsinomatozis açısından hasta ayrıntılı olarak incelenmelidir. LK'de mortalite oranı çok yüksek olduğu için hızlı bir şekilde BOS sitolojisi ve kontrastlı MRG dikkatli bir şekilde incelenerek tanı erken konmalı ve hasta için uygun tedavi protokolü belirlenmelidir. Hastalarda tanı ne kadar erken konulursa yaşam standartlarında iyileşme o kadar iyi olacağı için erken tanı önemlidir.

\section{Kaynaklar}

1. Corbin ZA, Nagpal S., 2016. Leptomeningeal metastases. JAMA Oncol. 2016; 2(6): 839

2. Gauthier H, Guilhaume MN, Bidard FC, Pierga JY, Girre V, Cottu $\mathrm{PH}$, et al. Survival of breast cancer patients with meningeal carcinomatosis. Ann Oncol. 2010;21(11): 2183-87.

3. Boogerd W, Dorresteijn LDA, van Der Sande JJ, De Gast GC, Bruning PF. (2000). Response of leptomeningeal me- tastases from breast cancer to hormonal therapy. Neurology 2000;55(1):117-19.

4. Chamberlain MC. Response of leptomeningeal metastases from breast cancer to hormonal therapy. Neurology 2001;56(3):425-26.

5. Chen LY, Ni YB, Lacambra MD, Lee WCK, Ho KKF, Tse GM. Skull bone metastasis with adjacent leptomeningeal involvement from pleomorphic lobular carcinoma of the breast. Histopathology 2015; 66(7): 1051-53.

6. Huang Z, Sun B, Wu S, Meng X, Cong Y, Shen G, et al. A nomogram for predicting survival in patients with breast cancer brain metastasis. Oncol Lett. 2018;15(5): 7090-96.

7. Le Rhun E, Rudà R, Devos P, Hoang-Xuan K, Brandsma D, Segura PP, et al. (2017). Diagnosis and treatment patterns for patients with leptomeningeal metastasis from solid tumors across Europe. J Neurooncol 2017; 133(2):419-27. 